\title{
Percutaneous left heart pressure measurements: an aid in the selection of patients for surgery
}

\author{
W. H. B A I N, R. M. THOMSON, AND W. A. M ACKEY \\ From the Cardiovascular Surgical Unit, Glasgow Royal Infirmary
}

The selection of patients with mitral and aortic valve disease for surgery can usually be made from the clinical, radiological, and electrocardiographic data. In a significantly large proportion of cases, however, more direct measurements of the haemodynamic effects of the valve lesion add valuable information. This communication concerns the use of percutaneous needle puncture of the chambers of the left heart, the aorta, and the pulmonary artery in the assessment of some cases of valvular disease. It is based on an analysis of more than 300 diagnostic procedures.

The suprasternal route described by Radner (1955) has been used to reach the aorta, pulmonary artery, and left atrium, and that described by Brock, Milstein, and Ross (1956) for the left ventricle. By using two needles simultaneously records were obtained routinely of the pressure gradients across the mitral and aortic valves, as well as the phasic and mean pulmonary pressures and the form of the left atrial pressure waves.

The records obtained have been correlated with the operative findings in the 183 patients who subsequently underwent valvotomy.

The techniques used have been modified slightly from those described by the originators (Radner, 1955 ; Brock et al., 1956). It has been our practice to employ general anaesthesia on the grounds that this makes the procedure more acceptable to the patient as well as providing a steadier haemodynamic state. The measurements can be made in about 10 minutes, and the quality of the pressure records is strikingly superior to that obtained through a catheter.

The method has not been widely adopted until recently, presumably because of the potential risks associated with blind needle puncture of the great vessels and heart. In the past two years, however, several authors have reported series with an acceptably small incidence of complications (Willman, Hanlon, Symbas, Kelly, and Mudd, 1964 ; Hansen, Fabricius, Pedersen, and Sandøe, 1962 ; Blackburn and Fleming, 1964). Certainly the occurrence of serious incidents is less than that reported after alternative methods of left heart catheterization (Susmano and Carleton, 1964; Russell, Carroll, and Hood, 1964; McIntosh, Whalen, Hernandez, Morris, and Miller, 1961 ; Adrouny, Sutherland, Griswold, and Ritzmann, 1963). In our experience, two precautions require emphasis-the needles should not be larger than No. 19 B.W.G., and the procedure appears to carry an extra risk in patients with gross elevation of the pulmonary pressures. There have been two deaths in this series of over 300 procedures ; death occurred in both cases in patients with a mean pulmonary pressure of more than $70 \mathrm{~mm} . \mathrm{Hg}$ and was delayed for 24 hours after the puncture. At necropsy no direct cause of death was found. The site of the punctures could be seen in the great vessels, but there was no significant intrapericardial or mediastinal bleeding. Both patients died after several hours of progressive hypotension, dyspnoea, and cyanosis and tachycardia associated with pre-existing auricular fibrillation. As a result of this experience we would employ alternative methods in patients in whom severe pulmonary hypertension is suspected.

The extra data obtained by this procedure have proved valuable in four groups of patients: those in whom the signs and symptoms are not in accord; those patients with mitral valve disease who also have obstructive pulmonary disease; cases of combined mitral and aortic valve disease ; and cases of mitral re-stenosis.

Typical of the first group is the patient who is discovered to have mitral stenosis at routine chest radiography, who has physical signs and E.C.G. abnormalities, but who denies incapacity. Rapid cardiac decompensation may occur in these patients in response to an additional work demand, and in particular pregnancy may tip the balance (Short and Brunnen, 1963). It has been our practice to recommend valvotomy to these patients if the pressure measurements reveal a significant elevation of pulmonary pressures and 
a correspondingly significant mitral diastolic gradient. Another group at risk is children with congenital aortic stenosis; assessment of the degree of obstruction is frequently difficult from assessment of the symptomatology and the radiological or electrocardiographic findings. Direct measurement of the systolic gradient across the aortic valve gives a clearer guide to the need for surgery.

The second group refers to those patients with abnormal respiratory function tests about whom there is doubt whether the predominant lesion is pulmonary or at the mitral valve. In the present series $28 \%$ fall into this group.

Where mitral and aortic stenosis coexist, the relative importance of each lesion can be quantitated best by measuring the relevant pressures, and the appropriate surgical procedure can then be planned.

The last group comprises some cases of mitral re-stenosis. Both the morbidity and mortality rat $\mathrm{s}$ are higher after the second operation than after a first valvotomy ; and many of the patients with re-stenosis may be candidates for valve replacement. We have used the percutaneous technique to confirm the presence of re-stenosis and to measure the pulmonary vascular resistance, since this factor has been clearly related to the mortality rate where open-heart surgery is required.

The diagnostic value of left heart pressure measurements depends fundamentally on there being a good correlation between the pressure gradient and the degree of stenosis. We have made this correlation in 183 patients who underwent surgery after diagnostic left heart puncture.

Figure 1 shows that there is a fair correlation between the mean diastolic gradient from left atrium to left ventricle and the degree of mitral valve obstruction. In preparing this graph, the presence of subvalvular stenosis was taken into account in assessing the mitral orifice. A similar relationship, which is found between the mean pulmonary arterial pressure and the functional orifice size, is shown in Figure 2.

The corresponding figures in patients with some mitral incompetence were grouped separately, and Figs 3 and 4 show that the presence of mitral incompetence is associated with pulmonary pressures and a diastolic gradient which are significantly higher for each orifice size than in cases of pure stenosis. Most of these pressures were measured without simultaneous estimation of the cardiac output, and variations in flow could account for the wide range of pressures. In the last 65 investigations, cardiac output has been measured by the Fick method during the pro-

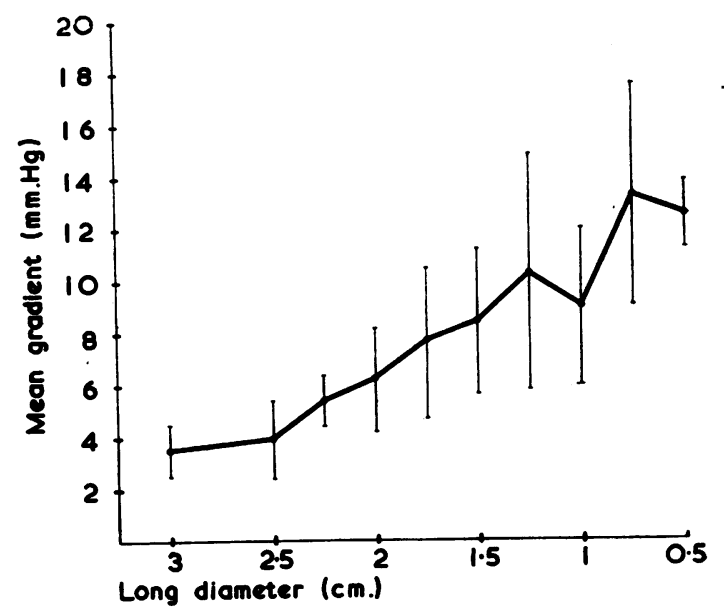

FIG. 1. Shows the correlation between the mean diastolic gradient and the size of the functional mitral orifice.

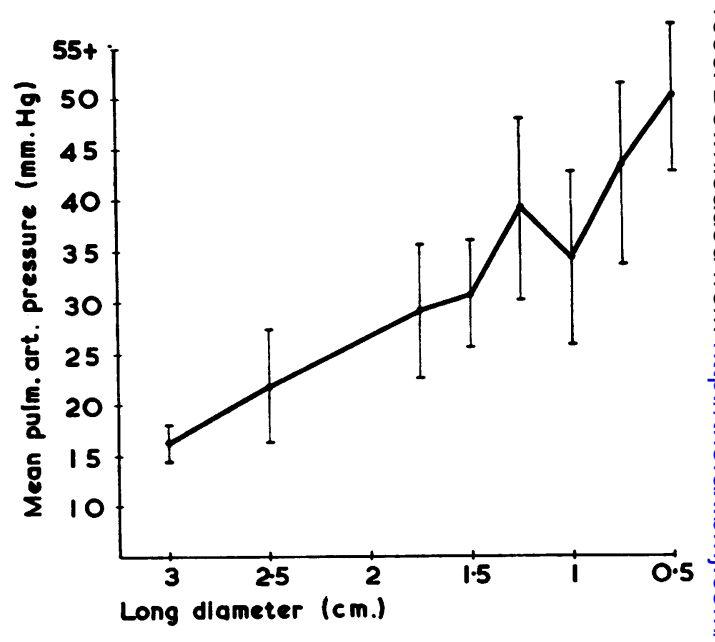

FIG. 2. Shows the correlation between the mean pulmonary 윽 arterial pressure and the size of the functional mitral orifice. cedure, and this factor has been included in the correlation shown in Figure 5. The degree of $\sigma$ obstruction at the mitral valve is expressed as the $N$ mean diastolic gradient divided by the cardiac $\underset{\mathrm{N}}{N}$ output, and this figure for resistance to flow is related to the functional orifice found at operation. A needle in the left atrium also allows $\frac{D}{\varnothing}$ recording of the left atrial wave form, and in $\stackrel{\infty}{+}$ common with many investigators we have tried 0 to use the left atrial ' $v$ ' wave as a means of ${ }^{\circ}$ quantitating mitral incompetence. Of the several $\stackrel{\mathbb{Q}}{\Omega}$ different ways of measuring the ' $v$ ' wave which have been described, it seemed that in the context $\frac{\Omega}{O}$ of mitral incompetence its relationship to the left 


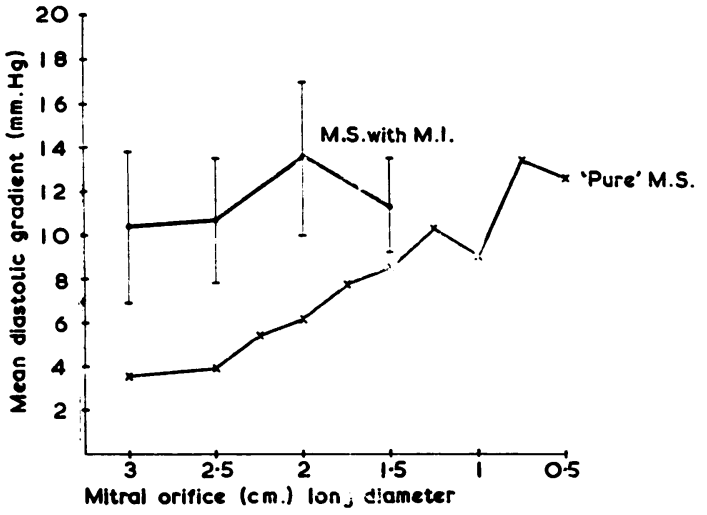

FIG. 3. Shows elevation of the diastolic gradient due to mitral incompetence.

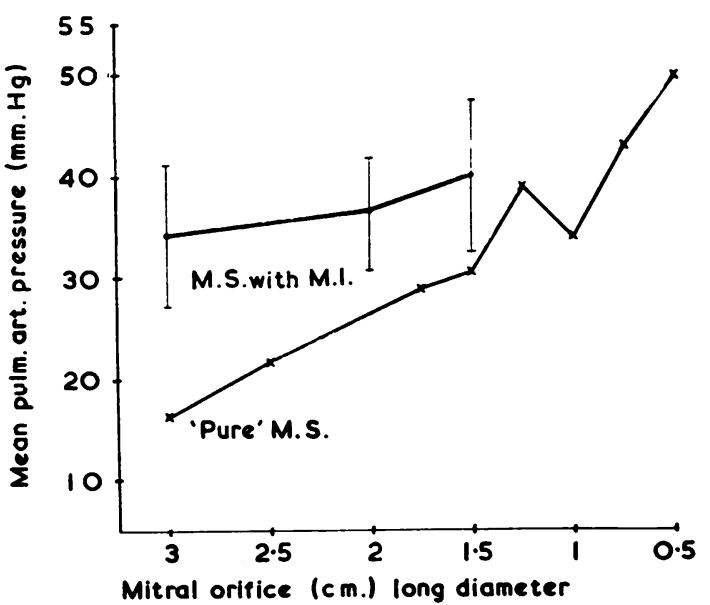

FIG. 4. Shows elevation of the mean pulmonary arterial pressure due to mitral incompetence.

ventricular pressure would be most relevant. For the results shown in Fig. 6 the left atrial ' $v$ ' wave has been measured as the vertical height from the ' $y$ ' trough to the peak of the ' $v$ ' wave, and this figure is expressed as a percentage of the ventricular pressure (measured from peak to early diastolic pressure). Figure 6 is a frequency histogram to show the heights of the ' $v$ ' wave in two groups of patients-one with pure stenosis, the other with associated incompetence. The figures show that ' $v$ ' waves of up to $20 \%$ of the ventricular peak pressure are equally distributed between the two groups. The four patients, however, in whom the ' $v$ ' wave was more than $25 \%$ of the ventricular pressure all had very significant mitral incompetence. One has subsequently died, two have had a mitral valve replacement operation,

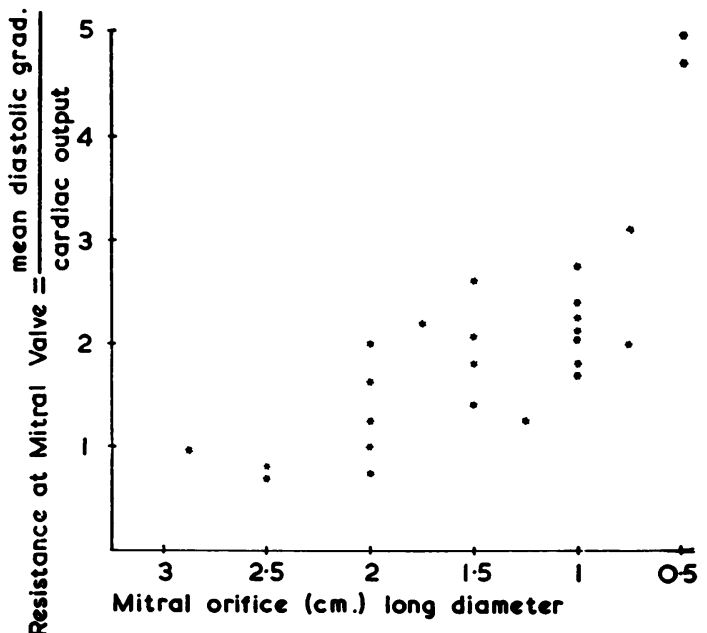

FIG. 5. The relationship between obstruction at the mitral orifice and its long diameter estimated at operation.

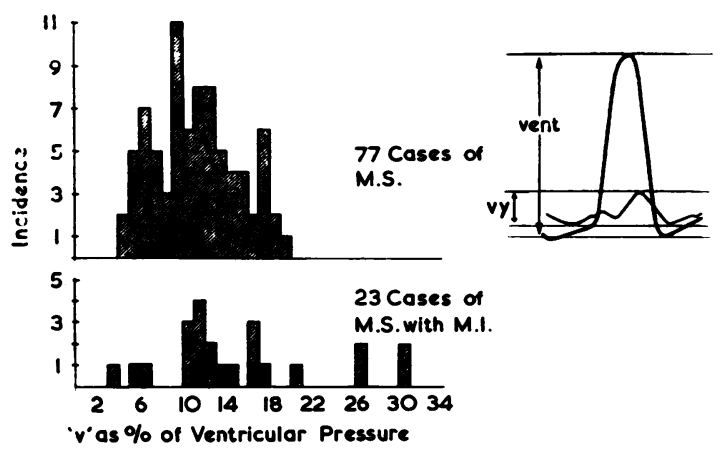

FIG. 6. A frequency histogram to show the occurrence of large left atrial ' $v$ ' waves in mitral valve disease.

and one is being managed on medical treatment for left heart failure. Several factors can influence the height and character of the left atrial ' $v$ ' wave. Chief among these was the size and distensibility of the left atrium and the pulmonary veins. In this study, however, no clear relationship was discernible between the ' $v$ ' wave and the size of the left atrium estimated radiologically and at operation.

In those patients in whom mitral incompetence is produced at valvotomy, the ' $v$ ' wave measured at the time is of considerable prognostic value, provided it is related to the ventricular pressure. In such patients, adaptive changes have not occurred and a significant increase in the height of the ' $v$ ' wave is indicative of a significant degree of iatrogenic incompetence (Table). 
T A B L E

EFFECT OF IATROGENIC MITRAL INCOMPETENCE ON THE LEFT ATRIAL ' $v$ ' WAVE (55 CASES)

\begin{tabular}{|c|c|c|c|}
\hline \multirow{2}{*}{ Surgeon's Description } & \multicolumn{3}{|c|}{ Change in $v y$} \\
\hline & Increased & Same & Decreased \\
\hline $\begin{array}{l}\text { Just palpable' ( } 27 \text { cases }) \\
\text { Moderate' ( } 21 \text { cases }) \\
\text { Marked' or 'significant' (7 cases) }\end{array}$ & $\begin{array}{r}17 \\
19 \\
6\end{array}$ & $\begin{array}{l}2 \\
1 \\
1\end{array}$ & $\begin{array}{l}8 \\
1 \\
0\end{array}$ \\
\hline
\end{tabular}

\section{SUMMARY}

Left heart pressure measurement by direct percutaneous puncture is a safe technique but should be used with circumspection in patients with gross pulmonary hypertension. The records obtained are a valuable aid to the selection of patients for surgery, but they must be interpreted in conjunction with other evidence in cases of stenosis with incompetence. The character of the left atrial wave form is of little diagnostic significance.

\section{REFERENCES}

Adrouny, Z. A., Sutherland, D. W., Griswold, H. E., and Ritzmann, L. W. (1963). Complications with transseptal left heart catheterization. Amer. Heart J., 65, 327.

Blackburn, J. P., and Fleming, P. R. (1964). Extended suprasternal puncture. Brit. Heart J., 26, 848.

Brock, R., Milstein, B. B., and Ross, D. H. (1956). Percutaneous left ventricular puncture in the assessment of aortic stenosis. Thorax, 11, 163.

Hansen, A. T., Fabricius, J., Pedersen, A., and Sandøe, E. (1962). Suprasternal puncture of the left atrium and the great vessels. Experience from 500 punctures. Amer. Heart J., 63, 443.

McIntosh, H. D., Whalen, R. E., Hernandez, R. R., Morris, J. J., and Miller, D. E. (1961). A potential hazard of the transseptal left atrial catheterization technic. Amer. J. Cardiol., 8, 835.

Radner, S. (1955). Extended suprasternal puncture technique. Acta med. scand., 151, 223.

Russell, R. O., Carroll, J. F., and Hood, W. G., Jr. (1964). Cardiac tamponade: a complication of the transseptal technic of left heart catheterization resulting in a fatality. Amer. J. Cardiol., heart cath 558 .
13,

Short, D., and Brunnen, P. L. (1963). The case for ignoring symptoms in assessing the severity of mitral stenosis. Brit. Heart J., 25, 695.

Susmano, A., and Carleton, R. A. (1964). Trans-septal catheterization of the left atrium: report of an unusual complication. New Engl. J. Med., $270,897$.

Willman V. L., Hanlon, C. R., Symbas, P. N., Kelly, J. J., and Mudd. J. G. (1964). Evaluation of cardiac function by suprasternal puncture. J. thorac. cardiovasc. Surg., 48, 959. 